\title{
Gambaran Komplikasi Penyakit Ginjal Kronik Non Dialisis di Poliklinik Ginjal-Hipertensi RSUP Prof. Dr. R. D. Kandou Periode Januari 2017 - Desember 2018
}

\author{
${ }^{1}$ Tasya U. S. Karinda \\ ${ }^{2}$ Cerelia E. C. Sugeng \\ ${ }^{2}$ Emma Sy. Moeis
}

\author{
${ }^{1}$ Program Studi Pendidikan Dokter Fakultas Kedokteran Universitas Sam Ratulangi Manado \\ ${ }^{2}$ Bagian Ilmu Penyakit Dalam Fakultas Kedokteran \\ Universitas Sam Ratulangi Manado \\ Email: tasya.karinda@ymail.com
}

\begin{abstract}
Chronic kidney disease (CKD) is still a global health problem with a rising prevalence in many countries. Complications of CKD are inter alia cardiovascular disease, hypertension, anemia, electrolyte disturbance, diabetes mellitus, and metabolic asidosis. This study was aimed to provide an overview of CKD at the Kidney-Hypertension polyclinic of Prof. Dr. R. D. Kandou Hospital. This was a descriptive retrospective study using data of CKD patients at the KidneyHypertension Polyclinic from January 2017 to December 2018. The results obtained 63 CKD patients consisting of $47.61 \%$ males and $52.38 \%$ females. Based on CKD staging, the eprcentages of patients were, as follows: stage 3 CKD (1.58\%), stage 4 CKD (22.22\%), and stage 5 CKD ND (76.19\%). Patients aged 50-59 years had the highest percentage of stage 5 ND CKD numbering 10 males $(20.83 \%)$ and 12 females $(25 \%)$. The prevalences of complications in stage 5 ND CKD compared to stage 4 CKD were, as follows: anemia $\mathrm{Hb} 11-11.9 \mathrm{~g} / \mathrm{dL}(77.5 \%$ vs $36.36 \%)$, uncontrolled hypertension $(37.50 \%$ vs $14.28 \%$ ), dyslipidemia (25\% vs $28.57 \%$ ), hyperurisemia (27.08\% in males and $41.67 \%$ in females vs $57.15 \%$ in males and $28.57 \%$ in females), hyponatremia ( $66.67 \%$ vs $64.28 \%)$, hypernatremia $(31.25 \%$ vs $0 \%)$, and hypokalemia ( $16.67 \%$ vs $35.72 \%$ ). In conclusion, CKD complications were anemia, hypertension, dyslipidemia, hyperurisemia, and electrolite imbalance; most were higher in stadium 5 ND CKD.
\end{abstract}

Keywords: chronic kidney disease, complications

\begin{abstract}
Abstrak: Penyakit ginjal kronik (PGK) masih menjadi masalah kesehatan global dan prevalensinya terus meningkat di berbagai negara. Komplikasi PGK antara lain penyakit kardiovaskular, hipertensi, anemia, gangguan elektrolit, diabetes melitus, dan asidosis metabolik. Penelitian ini bertujuan untuk mengetahui gambaran komplikasi PGK di Poliklinik GinjalHipertensi RSUP Prof. Dr. R. D. Kandou. Jenis penelitian ialah deskriptif retrospektif dengan menggunakan data pasien PGK yang dirawat di Poliklinik Ginjal-Hipertensi periode Januari 2017 - Desember 2018. Hasil penelitian mendapatkan 63 pasien PGK, terdiri dari 52,38\% perempuan dan 47,61\% laki-laki. Berdasarkan stadium PGK, PGK stadium 3 (1,58\%) orang, PGK stadium 4 $(22,22 \%)$, dan PGK stadium 5 ND (76,19\%). Kelompok usia tertinggi ialah 50-59 tahun. Prevalensi komplikasi pada PGK stadium 5 ND dibandingkan PGK stadium 4 ialah sebagai berikut: anemia $\mathrm{Hb} 11-11,9 \mathrm{~g} / \mathrm{dL}$ (77,5\% vs 36,36\%), hipertensi tidak terkontrol $(37,50 \%$ vs $14,28 \%$ ), dislipidemia ( $25 \%$ vs $28,57 \%$ ), hiperurisemia (27,08\% pada laki-laki dan $41,67 \%$ pada perempuan vs $57,15 \%$ pada laki-laki dan $28,57 \%$ pada perempuan), gangguan elektrolit hiponatremia $(66,67 \%$ vs $64,28 \%)$, hipernatremia $(31,25 \%$ vs $0 \%)$, dan hipokalemia $(16,67 \%$ vs $35,72 \%$ ). Simpulan penelitian ini ialah komplikasi PGK ialah anemia, hipertensi, dislipidemia, hiperurisemia, dan gangguan elektrolit; sebagian besar lebih banyak terjadi pada PGK stadium 5 ND.
\end{abstract}

Kata kunci: penyakit ginjal kronik, komplikasi 
Penyakit ginjal kronik (PGK) menurut Kidney Disease: Improving Global Outcomes (KDIGO) 2012, didefinisikan sebagai adanya penurunan laju filrasi glomerulus (LFG $<60 \mathrm{~mL} / \mathrm{menit} / 1,73 \mathrm{~m}^{2}$ ) dan kelainan ginjal seperti proteinuria, albuminuria, dan anatomi yang abnormal yang terjadi selama 3 bulan atau lebih. Albuminuria ditandai dengan laju ekskresi albumin $\geq 30 \mathrm{mg} / 24$ jam atau rasio albumin kreatinin $\geq 30 \mathrm{mg} / \mathrm{mmol}$, sedimen urin yang abnormal, dan gangguan elektrolit lainnya yang disebabkan oleh gangguan tubular ginjal, histologi yang abnormal, abnormalitas struktur melalui pencitraan juga riwayat transplantasi ginjal. ${ }^{1}$

Insidens PGK pada tahun 1995-1999 di Amerika Serikat, dilaporkan sekitar 100 kasus per juta penduduk per tahun. Angka ini terus meningkat sekitar $8 \%$ setiap tahunnya. Insiden di negara-negara berkembang lainnya diperkirakan sekitar 4060 kasus per juta penduduk per tahun. ${ }^{2}$ Berdasarkan Riset Kesehatan Dasar (Riskesdas) tahun 2018, prevalensi PGK di Indonesia meningkat sebesar 0,38\%. Di Indonesia, prevalensi PGK tertinggi di Kalimantan Utara $(0,64 \%)$, diikuti Maluku Utara $(0,56 \%)$, Sulawesi Utara $(0,53 \%)$, Gorontalo, Sulawesi Tengah, dan Nusa Tenggara Barat $(0,52 \%)$. Berdasarkan jenis kelamin, prevalensi PGK pada laki-laki sebesar $0,42 \%$ dan $0,35 \%$ pada perempuan. Menurut usia, prevalensi PGK tertinggi pada kelompok usia 65-74 tahun $(0,82 \%)$.

Penyebab PGK ialah diabetes mellitus, hipertensi, iskemia, infeksi, obstruksi, toksin, penyakit autoimun dan infiltratif. Penyakit ginjal kronik yang progresif dapat menimbulkan beberapa komplikasi dengan prevalensi dan intensitas yang lebih tinggi pada fungsi ginjal yang lebih rendah. Komplikasi yang dapat terjadi ialah penyakit kardiovaskular, hipertensi, anemia, kelainan tulang mineral, gangguan elektrolit, diabetes melitus, dan asidosis metabolik. Komplikasi ini berkontribusi pada morbiditas dan mortalitas yang tinggi serta memengaruhi kualitas hidup yang buruk. ${ }^{4}$ Anemia pada PGK dan gangguan mineral dan tulang pada PGK sering dimulai pada stadium 3, sedangkan hipertensi pada PGK mulai memburuk pada stadium 3-5. ${ }^{5}$

Sehubungan dengan peningkatan prevalensi PGK khususnya Sulawesi Utara, maka peneliti tertarik untuk melakukan penelitian mengenai gambaran komplikasi penyakit ginjal kronik non dialisis di Poliklinik Ginjal-Hipertensi RSUP Prof. Dr. R. D. Kandou. Diharapkan hasil penelitian ini dapat diaplikasikan dalam pencegahan progresifitas PGK.

\section{METODE PENELITIAN}

Penelitian ini dilakukan di Poliklinik Ginjal-Hipertensi RSUP Prof. Dr. R. D. Kandou Manado dengan menggunakan data pasien PGK 3, PGK 4, dan PGK 5 ND periode Januari 2017-Desember 2018. Jenis penelitian ialah deskriptif dengan desain potong lintang. Sampel penelitian ialah pasien yang terdiagnosis dengan PGK 3, 4, dan 5 ND di Poliklinik Ginjal-Hipertensi RSUP Prof. Dr. R. D. Kandou periode Januari 2017 - Desember 2018.

\section{HASIL PENELITIAN}

Hasil penelitian ini mendapatkan sebanyak 63 pasien yang masuk dalam kriteria inklusi, terdiri dari 33 orang $(52,38 \%)$ berjenis kelamin perempuan dan 30 orang $(47,61 \%)$ berjenis kelamin lakilaki. Berdasarkan stadium PGK, didapatkan PGK stadium 3 sebanyak 1 orang (1,58\%), PGK stadium 4 sebanyak 14 orang (22,22\%), dan PGK stadium 5 ND sebanyak 48 orang $(76,19 \%)$. Pada PGK stadium 3 tidak dibahas karena jumlah sampel yang didapat hanya ada 1 orang.

Tabel 1 memperlihatkan data sampel penelitian berupa usia, kadar hemoglobin $(\mathrm{Hb})$, tekanan darah sistolik (TDS), tekanan darah diastolik (TDD), kadar kolesterol total, HDL, LDL, trigliserida, asam urat, natrium $(\mathrm{Na})$, dan kalium $(\mathrm{K})$ dalam bentuk nilai minimal, nilai maksimal, dan rerata. 
Tabel 1. Karakteristik Sampel Penelitian

\begin{tabular}{lcccccc}
\hline \multirow{1}{*}{ Variabel } & \multicolumn{3}{c}{ PGK Stadium 4 } & \multicolumn{3}{c}{ PGK Stadium 5 ND } \\
& \multicolumn{3}{c}{$\mathrm{n}=14$} & & \multicolumn{3}{c}{$\mathrm{n}=48$} \\
& Min & Maks & Rerata & Min & Maks & Rerata \\
\hline Usia (tahun) & 44 & 78 & 58,07 & 48 & 83 & 63,81 \\
$\mathrm{Hb}(\mathrm{g} / \mathrm{dL})$ & 5,30 & 11,90 & 9,61 & 3,40 & 11,60 & 9,17 \\
$\mathrm{TDS}(\mathrm{mmHg})$ & 90 & 180 & 123,86 & 100 & 270 & 140,83 \\
TDD (mmHg) & 50 & 80 & 68,57 & 28 & 174 & 75,83 \\
Kol. Tot (mg/dL) & 127 & 307 & 187,64 & 106 & 288 & 176 \\
$\mathrm{HDL}(\mathrm{mg} / \mathrm{dL})$ & 23 & 101 & 40,64 & 16 & 88 & 40,40 \\
$\mathrm{LDL}(\mathrm{mg} / \mathrm{dL})$ & 37 & 189 & 107,86 & 40 & 206 & 104,27 \\
$\mathrm{TG}(\mathrm{mg} / \mathrm{dL})$ & 75 & 778 & 180,43 & 54 & 391 & 148,75 \\
$\mathrm{AU}(\mathrm{mg} / \mathrm{dL})$ & 5,80 & 14,10 & 9,13 & 3,70 & 17,70 & 8,12 \\
$\mathrm{Na} \mathrm{(mEq/L)}$ & 119 & 139 & 131,29 & 111 & 159 & 130,88 \\
$\mathrm{~K}(\mathrm{mEq} / \mathrm{L})$ & 2,30 & 5,50 & 4,20 & 2,30 & 7,09 & 4,42 \\
\hline
\end{tabular}

Tabel 2 menunjukkan bahwa pasien PGK 5 ND sebanyak 48 orang $(76,19 \%)$ dan yang terbanyak pada kelompok usia 50-59 tahun ialah PGK 5 ND, diikuti kelompok usia 40-49 tahun, kelompok usia 60-69 tahun, dan kelompok usia >70 tahun. Kelompok usia 30-39 tahun lebih banyak terjadi pada PGK 4.

Tabel 3 menunjukkan bahwa pasien PGK 5 ND paling banyak dengan $\mathrm{Hb} 11$ $11,9 \mathrm{~g} / \mathrm{dL}$ yaitu 31 orang $(77,5 \%)$ sedangkan pasien PGK 4 paling banyak dengan $\mathrm{Hb} 8-10,9 \mathrm{~g} / \mathrm{dL}$ yaitu 6 orang (54,54\%), diikuti dengan $\mathrm{Hb} 11-11,9 \mathrm{~g} / \mathrm{dL}$ yaitu 4 orang $(36,36 \%)$.

Tabel 4 menunjukkan bahwa baik pada pasien PGK 5 ND maupun PGK 4 lebih banyak terjadi hipertensi terkontrol (tekanan darah <140/90) yaitu 30 orang $(62,50 \%)$ vs 12 orang $(85,72 \%)$.

Tabel 5 menunjukkan bahwa baik pada
PGK 5 ND maupun PGK 4 lebih banyak terdapat pasien yang non dislipidemia yaitu 36 orang $(75 \%)$ vs 10 orang $(71,43 \%)$.

Tabel 6 menunjukkan bahwa baik pasien dengan PGK 5 ND maupun PGK 4 paling banyak dengan hiperurisemia yaitu 33 dari 48 orang vs 12 dari 14 orang.

Tabel 7 menunjukkan bahwa baik pasien dengan PGK 5 ND maupun PGK 4 paling banyak terjadi hiponatremia yaitu 32 orang $(66,67 \%)$ vs 9 orang $(64,28 \%)$.

Tabel 8 menunjukkan bahwa PGK 5 ND paling banyak dengan normokalemia yaitu 31 orang $(64,58 \%)$ diikuti dengan hiperkalemia sebanyak 9 orang $(18,75 \%)$ dan hipokalemia sebanyak 8 orang (16,67\%). Pada PGK 4 paling banyak dengan normokalemia yaitu 6 orang $(42,85 \%)$ kemudian hipokalemia sebanyak 5 orang $(35,72 \%)$ dan hiperkalemia sebanyak 3 orang $(21,43 \%)$.

Tabel 2. Prevalensi subjek PGK berdasarkan kelompok usia dan jenis kelamin

\begin{tabular}{ccccccc}
\hline $\begin{array}{c}\text { Kelompok usia } \\
\text { (tahun) }\end{array}$ & \multicolumn{3}{c}{ PGK Stadium 4 } & \multicolumn{3}{c}{ PGK Stadium 5 ND } \\
\hline $30-39$ & 2 & $\mathrm{P}$ & $\%$ & $\mathrm{~L}$ & $\mathrm{P}$ & $\%$ \\
$40-49$ & 3 & 2 & 35,71 & 7 & 6 & 27,08 \\
$50-59$ & 2 & 0 & 14,30 & 10 & 12 & 45,83 \\
$60-69$ & 2 & 1 & 21,42 & 1 & 8 & 18,75 \\
$>70$ & 0 & 0 & 0 & 1 & 1 & 4,17 \\
Total & & 14 & 100 & & 48 & \\
\hline
\end{tabular}


172 Jurnal e-Clinic (eCl), Volume 7, Nomor 2, Juli-Desember 2019

Tabel 3. Prevalensi anemia pada subjek PGK 4 dan PGK 5 ND

\begin{tabular}{cccccc}
\hline $\begin{array}{c}\text { Variabel } \\
\text { (g/dL) }\end{array}$ & \multicolumn{2}{c}{ PGK Stadium 4 } & \multicolumn{2}{c}{ PGK Stadium 5 ND } & Total \\
\hline $\mathrm{N}$ & $\%$ & $\mathrm{~N}$ & $\%$ & \\
$\mathrm{Hb} 11-11,9$ & 4 & 36,36 & 31 & 77,5 & 35 \\
$\mathrm{Hb}<10,9$ & 6 & 54,54 & 5 & 12,5 & 11 \\
Total & 1 & 9,10 & 4 & 10 & 5 \\
& 11 & 100 & 40 & 100 & 51 \\
\hline
\end{tabular}

Tabel 4. Prevalensi hipertensi pada subjek PGK 4 dan PGK 5 ND

\begin{tabular}{cccccc}
\hline \multirow{2}{*}{ Hipertensi } & \multicolumn{2}{c}{ PGK } & \multicolumn{2}{c}{ PGK } & \\
& \multicolumn{2}{c}{ Stadium 4 } & \multicolumn{2}{c}{ Stadium 5 ND } & Total \\
& $\mathrm{N}$ & $\%$ & $\mathrm{~N}$ & $\%$ & \\
\hline Terkontrol & 12 & 85,72 & 30 & 62,50 & 42 \\
\hline Tidak terkontrol & 2 & 14,28 & 18 & 37,50 & 20 \\
Total & 14 & 100 & 48 & 100 & 62 \\
\hline
\end{tabular}

Tabel 5. Prevalensi dislipidemia pada subjek PGK 4 dan PGK 5 ND

\begin{tabular}{|c|c|c|c|c|c|}
\hline \multirow{2}{*}{ Dislipidemia } & \multicolumn{2}{|c|}{ PGK Stadium 4} & \multicolumn{2}{|c|}{ PGK Stadium 5 ND } & \multirow{2}{*}{ Total } \\
\hline & $\mathrm{N}$ & $\%$ & $\mathrm{~N}$ & $\%$ & \\
\hline Dislipidemia & 4 & 28,57 & 12 & 25 & 16 \\
\hline Non dislipidemia & 10 & 71,43 & 36 & 75 & 46 \\
\hline Total & 14 & 100 & 48 & 100 & 62 \\
\hline
\end{tabular}

Tabel 6. Prevalensi hiperurisemia pada subjek PGK 4 dan PGK 5 ND

\begin{tabular}{lccccc}
\hline Variabel & \multicolumn{2}{c}{ PGK Stadium 4 } & \multicolumn{2}{c}{ PGK Stadium 5 ND } & Total \\
& $\mathrm{L}$ & $\mathrm{P}$ & $\mathrm{L}$ & $\mathrm{P}$ & \\
\hline Hiperurisemia & $8(57,15 \%)$ & $4(28,57 \%)$ & $13(27,08 \%)$ & $20(41,67 \%)$ & 45 \\
Non hiperurisemia & $1(7,14 \%)$ & $1(7,14 \%)$ & $7(14,58 \%)$ & $8(16,67 \%)$ & 17 \\
Total & \multicolumn{2}{c}{14} & & \multicolumn{2}{c}{48} \\
\hline
\end{tabular}

Tabel 7. Prevalensi gangguan elektrolit (natrium) pada subjek PGK 4 dan PGK 5 ND

\begin{tabular}{|c|c|c|c|c|c|}
\hline \multirow{2}{*}{ Variabel } & \multicolumn{2}{|c|}{ PGK Stadium 4} & \multicolumn{2}{|c|}{ PGK Stadium 5 ND } & \multirow{2}{*}{ Total } \\
\hline & $\mathrm{N}$ & $\%$ & $\mathrm{~N}$ & $\%$ & \\
\hline Hiponatremia & 9 & 64,28 & 32 & 66,67 & 41 \\
\hline Hipernatremia & 0 & 0 & 15 & 31,25 & 15 \\
\hline Normonatremia & 5 & 35,72 & 1 & 2,08 & 6 \\
\hline Total & 14 & 100 & 48 & 100 & 62 \\
\hline
\end{tabular}

Tabel 8. Prevalensi gangguan elektrolit (kalium) pada subjek PGK 4 dan PGK 5 ND

\begin{tabular}{lccccc}
\hline \multirow{2}{*}{ Variabel } & \multicolumn{2}{c}{ PGK Stadium 4 } & \multicolumn{2}{c}{ PGK Stadium 5 ND } & \multirow{2}{*}{ Total } \\
& $\mathrm{N}$ & $\%$ & $\mathrm{~N}$ & $\%$ & \\
\hline Hipokalemia & 5 & 35,72 & 8 & 16,67 & 13 \\
Hiperkalemia & 3 & 21,43 & 9 & 18,75 & 12 \\
Normokalemia & 6 & 42,85 & 31 & 64,58 & 37 \\
Total & 14 & 100 & 48 & 100 & 62 \\
\hline
\end{tabular}




\section{BAHASAN}

Pada penelitian ini, didapatkan kelompok usia yang memiliki prevalensi tertinggi PGK terjadi pada kelompok usia 50-59 tahun dengan PGK stadium $5 \mathrm{ND}$, terdiri dari 10 orang $(20,83 \%)$ laki-laki dan 12 orang $(25 \%)$ perempuan. Salah satu faktor risiko dari PGK ialah usia; oleh karena itu usia tua memiliki risiko lebih besar terjadi penurunan laju filtrasi glomerulus (LFG). Pada usia 40 tahun, jumlah nefron yang berfungsi berkurang setiap 10 tahun sekitar $10 \% .^{6}$ Penelitian di Spanyol oleh González et $\mathrm{al}^{7}$ melaporkan dari total subjek 97.665, perempuan $(57,3 \%)$ lebih banyak mengalami PGK dibandingkan laki-laki $(42,7 \%)$. Penyakit ginjal kronik dapat dipengaruhi oleh ras, faktor genetik, dan lingkungan. Berbagai faktor risiko yang dapat memengaruhi PGK yaitu riwayat hipertensi, diabetes melitus, infeksi saluran kemih, riwayat batu saluran kemih, dan obesitas.

Anemia merupakan salah satu komplikasi PGK. Hasil penelitian ini mendapatkan anemia banyak terjadi pada PGK stadium 5 ND $(77,5 \%)$ dengan kadar $\mathrm{Hb}$ 11-11,9 $\mathrm{g} / \mathrm{dL}$. Penelitian oleh Shaheen et $\mathrm{al}^{8}$ di Saudi Arabia menunjukkan bahwa pada PGK stadium 5 ND dengan $\mathrm{Hb} 11-12$ g/dL sebanyak $10 \%$ dari total 250 subjek. Pada saat ginjal mengalami kerusakan, maka produksi eritropoietin akan berkurang. Eritropoietin merupakan glikoprotein yang dikeluarkan oleh fibroblas interstisial ginjal dan penting untuk diferensiasi sel darah merah di sumsum tulang. Anemia pada PGK dapat disebabkan oleh berbagai mekanisme seperti defisiensi besi, asam folat, atau vitamin B12, perdarahan gastrointestinal, hiperparatiroidisme berat, peradangan sistemik, dan kelangsungan hidup eritrosit yang pendek. Penyebab utama terjadinya anemia pada PGK ialah produksi eritropoietin yang tidak adekuat. ${ }^{9}$ Prevalesi anemia terus meningkat ketika PGK berkembang; oleh karena itu perlu dilakukan skrining pada pasien PGK dengan anemia. Evaluasi anemia pada PGK, salah satunya ialah dengan melakukan tes status besi. Berdasrkan hasil tes tersebut, dapat dilakukan terapi ESA. ${ }^{10}$
Berdasarkan Konsensus Indonesian Society of Hypertension 2019 target tekanan darah (TD) pada pasien PGK ialah TDS <140 dan TDD < $90 .{ }^{11}$ Pada penelitian ini didapatkan bahwa lebih banyak kasus hipertensi terkontrol pada PGK stadium 4 $(85,72 \%)$. Penelitian yang dilakukan oleh Muntner et $\mathrm{al}^{12}$ di Amerika melaporkan bahwa pada pasien PGK dengan hipertensi sebanyak $67,1 \%$ memiliki tekanan darah $<140 / 90 \mathrm{mmHg}$. Hal ini dapat terjadi karena perubahan gaya hidup dan telah mendapatkan pengobatan antihipertensi yang bisa mengurangi risiko penyakit kardiovaskular. ${ }^{13}$

Kelainan lipid pada PGK ialah terjadi penurunan HDL atau peningkatan TG, LDL, dan kolesterol total. Kelainan lipid dapat meningkatkan risiko kardiovaskular. ${ }^{14}$ Pada penelitian ini didapatkan bahwa pasien dislipidemia lebih banyak terjadi pada PGK stadium 4 (28,57\%). Pada pasien PGK, semakin menurun fungsi ginjal maka semakin banyak VLDL yang kaya akan TG terakumulasi di ginjal. Trigliserida yang tinggi disebabkan oleh kadar lipoprotein lipase menurun. Selain itu, lipoprotein ApoB yaitu LDL-C umumnya meningkat pada PGK. ${ }^{15}$ Rekomendasi dari KDIGO, terapi pada dislipidemia dengan menggunakan statin pada usia $\geq 50$ tahun dengan $\mathrm{LFG}<60 \mathrm{ml} / \mathrm{min} / 1,73 \mathrm{~m}^{2}$ dan tidak dalam terapi hemodialisis atau transplantasi ginjal. $^{1}$

Hiperurisemia pada PGK terjadi karena penurunan ekskresi asam urat. ${ }^{16}$ Pada penelitian ini didapatkan bahwa pasien dengan hiperurisemia lebih banyak pada PGK stadium 4, terdiri dari $57,15 \%$ laki-laki dan 28,57\% perempuan. Menurut Adejumo et al $^{17}$ di Southern Nigeria, prevalensi hiperurisemia $(47,1 \%)$ lebih tinggi daripada yang tidak menderita hiperurisemia (15\%). Hiperurisemia dapat terjadi karena diet purin dan fruktosa, perubahan gaya hidup, dan dosis obat allopurinol.

Gangguan elektrolit yang dimaksud pada penelitian ini ialah kadar abnormal dari natrium dan kalium. Natrium yang abnormal terdiri dari hiponatremia dan 
hipernatremia, sedangkan untuk kalium yang abnormal ialah hipokalemia dan hiperkalemia. Hasil penelitian ini mendapatkan bahwa gangguan elektrolit lebih banyak terjadi pada PGK stadium 5 ND yaitu hiponatremia sebanyak $66,67 \%$. Pada PGK, sekresi dan reabsorpsi keseimbangan elektrolit terganggu sehingga dapat terjadi kadar abnormal dari natrium atau kalium. ${ }^{18,19}$ Penelitian oleh Draz et al ${ }^{20}$ melaporkan bahwa prevalensi hiponatremia sebesar $32 \%$ dan hiperkalemia sebesar $25 \%$.

\section{SIMPULAN}

Berdasarkan hasil penelitian ini dapat disimpulkan bahwa komplikasi PGK ialah anemia, hipertensi, dislipidemia, hiperurisemia, dan gangguan elektrolit; sebagian besar lebih banyak terjadi pada PGK stadium 5 ND.

Penelitian ini merupakan penelitian deskriptif retrospektif yang menggunakan data sekunder. Diperlukan penelitian lebih lanjut dengan metode analitik sehingga bisa mengetahui hubungan antara variabelvariabel tersebut.

\section{DAFTAR PUSTAKA}

1. Kidney Disease: Improving Global Outcomes (KDIGO) CKD Work Group. KDIGO 2012 Clinical practice guidline for the evaluation and management of chronic kidney disease. Kidney Int Suppl 2013;3:1-150.

2. Suwitra K. Penyakit ginjal kronik. In: Sudoyo A, Setiyohadi B, Alwi I, Simadibrata K M, Setiati S, editors. Buku Ajar Ilmu Penyakit Dalam (6th ed). Jakarta: InternaPublishing, 2014; p. 2159-241.

3. Riset Kesehatan Dasar (Riskesdas 2018) Laporan Nasional 2018. Jakarta: Badan Penelitian dan Pengembangan Kesehatan Departemen Kesehatan Republik Indonesia, 2018.

4. Bello AK, Alrukhaimi M, Ashuntantang GE, Basnet S, Rotter RC, Douthat WG, et al. Complications of chronic kidney disease: current state, knowledge gaps, and strategy for action. Kidney Int Suppl (2011). 2017;7(2):122-9.

5. American Society of Nephrology. Clinical Practice Recommendations for Primary
Care Physicians and Healthcare providers. Yee J, Krol GD, editors. 2010;6:4-53.

6. Sulistiowati E, Idaiani S. Faktor risiko penyakit ginjal kronik berdasarkan analisis cross-sectional data awal studi kohort penyakit tidak menular penduduk usia 25-65 tahun di Kelurahan Kebon Kalapa, Kota Bogor Tahun 2011. Buletin Penelitian Kesehatan. 2015;43(3):163-72.

7. González B, Pascual M, Guijarro L, González A, Puertolas O, Latre LM. Chronic kidney disease in Primary Health Care: Prevalence and associated risk factors. Aten Primaria. 2015;47(4): 236-45.

8. Shaheen F, Souqiyyeh MZ, Al-Attar BA, Karkar A, Al Jazairi AM, Badawi LS, et al. Prevalence of anemia in predialysis chronic kidney disease patients. Saudi J Kidney Dis Transpl. 2011;22(3):456-63.

9. Thomas R, Kanso A, Sedor JR. Chronic kidney disease and its complications. Prim Care. 2008;35(2):329-vii.

10. Rivera RF. Anemia in patients with chronic kidney disease: current screening and management approaches. Nephrol Renal Dis. 2016;1(1):1-9.

11. Indonesian Society of Hypertension. Konsensus Penatalaksanan Hipertensi, 2019.

12. Muntner P, Anderson A, Charleston J, Chen Z, Ford V, Makos G, et al. Hypertension awareness, treatment, and control in adults with CKD: results from the Chronic Renal Insufficiency Cohort (CRIC) Study. American Journal of Kidney Diseases: the official journal of the National Kidney Foundation. 2010;55(3):441-51.

13. Rajati F, Hamzeh B, Pasdar Y, Safari R, Moradinazar M, Shakiba E, et al. Prevalence, awareness, treatment, and control of hypertension and their determinants: Results from the first cohort of non-communicable diseases in a Kurdish settlement. Sci Rep. 2019;9:12409. Available from: https://doi.org/10.1038/s41598-01948232-y

14. Webster AC, Nagler EV, Morton RL, Masson P. Chronic kidney disease. Lancet. 2017;389(10075):1238-52. 
15. Schuchardt M, Tölle M, van der Giet $M$. High-density lipoprotein: structural and functional changes under uremic conditions and the therapeutic consequences. In: von Eckardstein A, Kardassis D (editors). High Density Lipoproteins. Handbook of Experimental Phrmacology. Springer, Cham. 2015;224:423-53. DOI 10.1007/978-3319-09665-0_13

16. Prasad Sah OS, Qing YX. Associations between hyperuricemia and chronic kidney disease: a review. Nephrourol Mon. 2015;7(3):e27223. .

17. Adejumo OA, Okaka EI, Ojogwu LI. Lipid profile in pre-dialysis chronic kidney disease patients in Southern Nigeria. Ghana Med J. 2016;50(1):449.

18. Widya WH. Terapi Cairan dan Elektrolit Perioperatif. Bandung: Fakultas Kedokteran Universitas Padjajaran; 2007.

19. National Kidney Foundation. Clinical Update on Hyperkalemia, 2014; p. 2-4.

20. Hamed AD, Atef GH, Reda AK , Mahmoud AB. Study of the prevalence of sodium and potassium disturbances in the elderly. ZUMJ. 2019; 25(6):825-34. 